
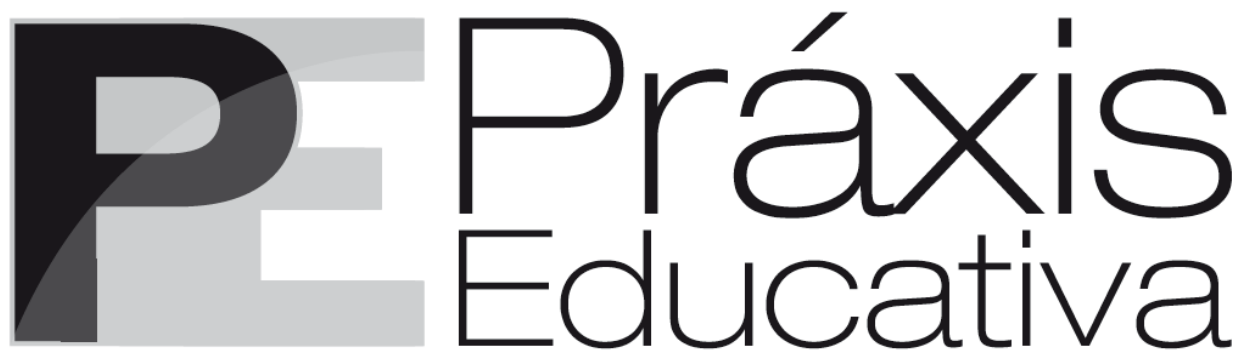

ISSN 1809-4031

eISSN 1809-4309

Entrevista

\title{
Uma história de pioneirismo: entrevista com a Professora Maria Piedade Resende da Costa
}

\author{
Maria Piedade Resende da Costa ${ }^{*}$ \\ iD https://orcid.org/0000-0002-7420-5602 \\ Norma Abreu e Lima Maciel de Lemos Vasconcelos ${ }^{* *}$ \\ (D) https://orcid.org/0000-0002-4927-0760 \\ Luiz Renato Martins da Rocha** \\ iD https://orcid.org/0000-0002-2884-4956
}



A entrevista com a Prof. ${ }^{a}$ Dr. ${ }^{a}$ Maria Piedade Resende da Costa, professora permanente do Programa de Pós-Graduação em Educação Especial da Universidade Federal de São Carlos (UFSCar), foi realizada de forma online, devido à pandemia da Covid-19, entre os dias 1 e 31 de maio de 2021, por dois de seus ex-alunos da UFSCar, a Prof. ${ }^{a}$ Dr. ${ }^{a}$ Norma Abreu e Lima Maciel de Lemos Vasconcelos e o Prof. Dr. Luiz Renato Martins da Rocha.

\footnotetext{
* Professora do Programa de Pós-Graduação em Educação Especial da Universidade Federal de São Carlos (UFSCar). Doutora em Psicologia. E-mail: <piedade@ufscar.br>.

** Professora da Universidade de Pernambuco. Doutora em Educação Especial. E-mail: <normamvasconcelos@yahoo.com.br>.

*** Tradutor e Intérprete de Libras/Língua Portuguesa. Universidade Tecnológica Federal do Paraná. Doutor em Educação Especial. E-mail: <luizrocha@utfpr.edu.br>.
} 


\section{Uma breve apresentação da Professora Maria Piedade Resende da Costa}

Queremos aqui mergulhar um pouco no passado da Professora Maria, no início de sua vida acadêmica, para melhor situarmos o leitor sobre a sua trajetória de formação e de transformação. Seu currículo mostra-nos que, em 1957, foi dada a largada para sua vida profissional com o ingresso no Curso Pedagógico do Instituto de Educação de Pernambuco. No ano seguinte, houve sua aprovação no vestibular e a entrada no Curso de Belas Artes do Recife. Paralelamente, ela frequentou o curso ministrado pela Professora Anita Paes Barreto, sobre os ensinamentos e sistematização dos procedimentos para a alfabetização no Movimento de Cultura Popular (MCP). Foi discípula de renomados mestres pernambucanos, como os Professores Sylvio Rabelo, Estevão Pinto, Anita Paes Barreto, Olívia Pereira, Lula Cardoso Aires, Paulo Freire, entre outros.

Na década seguinte, a Professora Piedade ampliou seus conhecimentos ao percorrer áreas da deficiência. Ela realizou um curso para professores de surdos no Instituto Domingos Sávio para Surdos (Instituição pioneira na educação desses estudantes em Pernambuco) e, logo em seguida, passou a fazer parte do quadro docente, quando conheceu e iniciou uma longa amizade com o Padre Vicente de Paulo Burnier, primeiro padre surdo do Brasil, ordenado no Vaticano em 1951. Em 1964, em Minas Gerais, a Professora Piedade fez um estágio na Fazenda do Rosário com a ilustre professora Helena Antipoff, onde havia atendimento para as crianças com dupla excepcionalidade: surdez e deficiência intelectual.

Vale ressaltarmos também seu empenho e sua contribuição no processo para o estabelecimento da profissão de Fonoaudiologia, uma vez que, em 1965, ela participou da criação da Associação Pernambucana de Logopedia e, prosseguindo com muitas lutas e desafios, contribuiu para a criação da profissão de Fonoaudiologia em 1981, quando obteve sua aprovação pelo Congresso Nacional. Logo em seguida, após rigorosa análise dos currículos pelo Conselho provisório de Fonoaudiologia, a Professora Piedade obteve o título de Fonoaudióloga juntamente a outros colegas que exerciam também a atividade de terapeuta da palavra. E, assim, cada vez mais, foi se apropriando daquilo que mais tarde iria desenvolver com tanta maestria, sua vida profissional, voltada à Educação Especial.

A Professora Piedade é doutora em Psicologia Experimental pela Universidade de São Paulo - USP (1992), mestre em Educação Especial pela UFSCar (1984), psicóloga e pedagoga pela Universidade Católica de Pernambuco (UNICAP). Logo após concluir seu Mestrado, foi aprovada no concurso da UFSCar e assumiu a docência no Departamento de Fundamentos Científicos e Filosóficos da Educação e no Programa de Mestrado em Educação Especial. Aposentou-se em 1992, mas não parou; ela continuou na mesma Instituição, exercendo suas atividades como Professora Sênior do Departamento de Psicologia e Professora permanente no Programa de PósGraduação em Educação Especial, além de várias orientações de Trabalhos de Conclusão de Curso (TCC), de Mestrado, Doutorado e supervisões de Pós-Doutorado.

Com uma longa caminhada, sua história não se esgota aqui, nem daríamos conta de tantas conquistas, avanços e desafios de uma mulher guerreira, sonhadora, vencedora, desbravadora e que tanto contribuiu e ainda contribui, para o desenvolvimento da área da Educação Especial no Brasil. Vejamos a seguir o que ela tem para nos contar!

Norma e Luiz Renato: Professora Piedade, o que a senhora teria a destacar sobre a sua rica trajetória profissional?

MP - Gostaria de destacar que, durante meu percurso profissional de 60 anos exercendo atividades, tenho acompanhado a história da área da Educação Especial. Tenho visto muitos avanços e conquistas. Posso relatar que praticamente participei das várias etapas dessa modalidade

Práxis Educativa, Ponta Grossa, v. 16, e2118156, p. 1-10, 2021 Disponível em: < https://www.revistas2.uepg.br/index.php/praxiseducativa $>$ 
de ensino. É uma coisa muito boa! É excelente rever alguns degraus dessas conquistas. Inicialmente, lembro que, nas décadas de 1960 e 1970, todas as referências bibliográficas sobre Educação Especial, nas quais estudei, eram traduzidas. Os métodos, as atividades, os recursos, enfim, quase tudo que era aplicado em sala de aula com nossos alunos da Educação Especial era traduzido dos livros dos Estados Unidos, da Europa ou da Argentina. Posso ousar dizer que havia uma Educação Especial copiada de outros países.

Norma e Luiz Renato: Com expressiva atuação na área da Educação para pessoas com deficiência e inclusão, a professora construiu um legado que nos contempla com uma produção bibliográfica na área de Educação Especial. Como ocorreu o início da pesquisa em sua vida acadêmica?

MP - É uma caminhada muito longa. Quero inicialmente informar que, desde 1960, sempre trabalhei diretamente ensinando a pessoa com deficiência na sala de aula. Na década de 1970, surgiu o Centro Nacional de Educação Especial (Cenesp) por meio do Decreto no 72.425 , de 3 de julho de 1973, o primeiro como órgão responsável pela definição da política de Educação Especial nacional. Anteriormente, as áreas de deficiência visual, surdez e deficiência intelectual trabalhavam isoladas. Foi um grande avanço porque a Educação Especial passou a ter uma organização centralizada e planejada nacionalmente. Não havia uma política para a formação do pesquisador. Uma das políticas do Cenesp foi o programa para a formação de recursos humanos para a Educação Especial. Para a concretização desse programa, vale salientar outro fato importante: o Cenesp fez convênio com a Coordenação de Aperfeiçoamento de Pessoal de Nível Superior (Capes). Um dos primeiros cursos foi realizado pela Pontifícia Universidade Católica do Rio de Janeiro (PUC/Rio). Fui selecionada para realizar o curso de aperfeiçoamento na PUC/Rio, porque exercia minhas atividades diretamente como professora de alunos surdos. Paralelamente, o convênio Cenesp/Capes selecionou professores que exerciam a função junto à Educação Especial para cursar o Mestrado nos Estados Unidos. Começava o investimento do Cenesp na formação dos futuros pesquisadores em Educação Especial. Após concluírem o Mestrado nos Estados Unidos e retornarem ao Brasil, os recém mestres começaram a organizar e a ministrar os cursos de especialização. No ano de 1977, novamente, dando continuidade à política de formação de recursos humanos pelo convênio Cenesp/Capes, fui selecionada e fiz o curso de Especialização em Educação Especial na Universidade Metodista de Piracicaba (Unimep). Logo depois, fui convidada pela Universidade Federal da Paraíba (UFPB), em convênio com o Cenesp, para ministrar uma disciplina no curso de formação de recursos humanos para professores da Educação Especial no estado da Paraíba. Em seguida, por meio de concurso público, dei início à minha carreira acadêmica. Fui aprovada como professora do Departamento de Metodologia de Ensino da UFPB e juntamente a duas colegas participamos das atuações embrionárias do futuro Núcleo de Educação Especial (NEDESP) da UFPB. Esse projeto era voltado tanto aos estudantes da Universidade quanto à população público-alvo da Educação Especial da comunidade, além de oferecer apoio aos professores das redes estaduais e municipais. Foi o primeiro passo para o início da pesquisa na minha vida. Entretanto, havia a ausência de incentivos para a divulgação dos resultados tanto por meio das publicações em revistas científicas como nos eventos científicos, devido à sua carência.

\section{Norma e Luiz Renato: Como foi a sua saída da UFPB para o ingresso na UFSCar?}

MP - Em 1981, ainda como investimento em recursos humanos do convênio Cenesp/Capes, tive acesso ao edital sobre o processo seletivo para o Programa de Mestrado em Educação Especial (PMEE) da UFSCar. Fiz minha inscrição e, após a aprovação na seleção, iniciei o Mestrado. Entretanto, na época, o Programa não era contemplado com bolsas porque estava iniciando e, com a nossa aprovação, passou a ter bolsas da Capes como continuação da política 
nacional para investimento no Programa de Formação de Recursos Humanos para a Educação Especial a nível de Pós-Graduação stricto sensu.

Minha pesquisa para a dissertação foi sobre a sistematização de um procedimento para o ensino da leitura e escrita (alfabetização) para aluno com deficiência intelectual treinável (classificação da época). Tratava-se de um procedimento que já aplicava com meus alunos desde a década de 1960. No entanto, não havia uma fundamentação teórica. Justamente, foi a pesquisa que me deu esse respaldo.

É importante salientar que, na época, participei de eventos como a $12^{\mathrm{a}}$ Reunião Anual de Psicologia, em 1982, a $2^{a}$ Jornada Científica da UFSCar, em 1982, a 35 Reunião Anual da SBPC [Sociedade Brasileira para o Progresso da Ciência], em 1983, e a VI Reunião Anual da ANPEd [Associação Nacional de Pós-Graduação e Pesquisa em Educação], em 1983, para a divulgação dos dados da pesquisa do Mestrado.

Após a conclusão do Mestrado na UFSCar, retornei à UFPB. Em seguida, a UFSCar abriu um edital para concurso ao qual me submeti e fui aprovada como professora do Departamento de Fundamentos Científicos e Filosóficos da Educação. Na época, devido à carência de professores doutores, a Coordenação do PMEE solicitou e obteve, da Capes, a autorização para meu credenciamento, apenas com Mestrado, como orientadora do Programa conforme o Parecer $\mathrm{N}^{\circ}$ 383/92, aprovado em 29 de junho de 1992. Vale ressaltar, como dito anteriormente, que já exercia a atividade de professora do PMEE. Após a autorização, comecei a atuar no curso de Mestrado como orientadora. Paralelamente, iniciei, na USP/São Paulo, o curso de Doutorado, dando continuidade à minha formação como pesquisadora.

Norma e Luiz Renato: Sua trajetória profissional agracia-nos por inúmeros estudos, projetos, pesquisas e trabalhos inovadores, e, dentre eles, pelo seu pioneirismo. Destacamos aqui a implantação do Laboratório de Educação Especial da UFSCar, em 1985, e a formação de um dos primeiros Grupos de Pesquisa em Educação Especial, em 1992. Pode nos explicar como surgiu o Laboratório de Educação Especial da UFSCar?

MP - A semente que deu origem ao Laboratório de Educação Especial foi plantada durante o meu curso de Mestrado. Como aluna do Mestrado e anuência da Coordenação do Curso, comecei a realizar trabalhos na comunidade paralelamente às minhas atividades para a coleta de dados da minha pesquisa. Na época, já havia credibilidade sobre minhas atividades pedagógicas na comunidade.

Quando retornei a São Carlos, como professora da UFSCar, praticamente o caminho já estava aberto. Então, surgiu a ideia de organizar, na Universidade, um espaço adequado para o atendimento à comunidade. Vale salientar que já trazia a experiência da implantação inicial do futuro NEDESP da UFPB.

O Laboratório de Educação Especial surgiu com enfoque em duas vertentes: a necessidade apresentada pela comunidade sobre um atendimento especializado para alunos das escolas da rede pública de ensino e um espaço adequado para o desenvolvimento das pesquisas que pretendia desenvolver e também a do Doutorado. Após solicitação, o projeto do Laboratório foi aprovado pelo Conselho Departamental e teve início em agosto de 1985. 
Norma e Luiz Renato: O que o Laboratório representou na época?

MP - Representou um grande passo para a obtenção de entendimentos sobre o que estava ocorrendo na escola, espaço adequado para trabalhar diretamente com as professoras das primeiras séries, realizar as pesquisas e uma oportunidade para estágio de alunos. Portanto, nesse Laboratório, eu atuava na extensão - oferecendo o atendimento especializado para crianças da rede de ensino (municipal e estadual) e campo de estágio para alunos da Universidade; na pesquisa desenvolvendo projetos de pesquisa dos orientandos; e no ensino - ministrando aula.

Norma e Luiz Renato: Como surgiu seu interesse em desenvolver um projeto tão relevante para as pessoas com deficiência?

MP - Na época ocorria um fato preocupante nas primeiras séries de ensino regular. Várias crianças eram exímias "copistas", ou seja, só faziam copiar o que viam na lousa e nos livros. Os cadernos bem organizados pareciam demonstrar para os pais que ia tudo bem com a aprendizagem de seus filhos. E, quando a escola os comunicou que seus filhos não aprendiam a ler porque poderiam ter alguma deficiência e estavam sendo encaminhados para o setor da Psicologia de uma instituição especializada da comunidade, isso os deixou preocupados. Após as conclusões das avaliações pelo setor de Psicologia da instituição e a constatação de que não havia problemas de déficit nas crianças, elas foram encaminhadas pelas professoras para o atendimento no Laboratório com a queixa que não conseguiam aprender a ler. Aliás, parece-me um fato recorrente porque o problema da alfabetização continua até hoje.

Por que o encaminhamento para o Laboratório de Educação Especial? Porque era o único local que poderia atender à criança sem envolvimento de ônus financeiros. Surgiu, assim, a questão: Por que atender à criança sem déficit intelectual se o Laboratório tinha como objetivo atender à população da Educação Especial com recursos financeiros reduzidos e residente na comunidade? Então, resolvi, como coordenadora do Laboratório, atender à criança, já com 10, 11 ou mais anos e sem déficit, porque, caso não o fizesse, provavelmente ela poderia não conseguir aprender a ler e caminharia para fazer parte de mais um adulto analfabeto.

Surgiu, então, outra questão: Por que uma criança com déficit intelectual aprende a ler e a sem déficit não consegue? Antes de iniciar o atendimento à criança, fiz uma sondagem junto às suas professoras, com a aplicação de um instrumento. A conclusão dos dados obtidos na sondagem foi que o problema não estava no professor e nem no aluno. Os achados, de um modo geral, foram interessantes. Por exemplo, foi constatado: lacunas quanto ao conhecimento básico, por parte dos professores, sobre os aspectos perceptuais fundamentais para a aquisição da leitura; desconhecimento de uma fundamentação teórica para o ensino da leitura e da escrita, ou seja, da alfabetização; desconhecimento sobre o processo para a alfabetização; desconhecimento sobre a teoria que fundamentava sua opção para ensinar a leitura e a escrita, entre outros aspectos. Outro achado importante: as professoras participavam de vários cursos de formação continuada e demonstravam angústia e interesse em buscar novos conhecimentos sobre o tema. Parece-me que, na época, havia uma lacuna na formação inicial e as professoras buscavam incessantemente os conhecimentos na formação continuada.

O que fazer? O que propor? Seria, por um lado, uma opção complicada para a escolha da atuação no atendimento aos alunos "copistas"; e, por outro, não podia deixar o objetivo do Laboratório de Educação Especial. Segui uma opção que não causasse conflito para o aluno "copista" sem déficit cognitivo que continuava na escola sem ter aprendido a ler e que deveria seguir a rotina da série que frequentava e, paralelamente, estava frequentando o Laboratório para aprender a ler. Então, foi elaborado o projeto. Por tratar-se de intervenção pedagógica no Laboratório, os 
relatos dos atendimentos ficaram restritos à ficha de acompanhamento de cada aluno. Poderiam servir como dados de pesquisa, mas essa não era a intenção porque a intervenção pedagógica realizada era óbvia, comum e a escola poderia ter realizado há muito tempo, evitando assim traumas que a criança estava passando.

Norma e Luiz Renato: Poderia nos falar um pouco sobre as suas ações na área de alfabetização de pessoas com deficiência?

MP - Sim. Realizei várias ações na área de alfabetização de pessoas com deficiência. Posso citar como exemplo na deficiência física. Anteriormente, durante o Mestrado, fui procurada por professores da UFSCar, dos cursos de Fisioterapia e de Terapia Ocupacional, juntamente à família de uma criança com deficiência física como consequência da poliomielite. Veja como faz tempo. Hoje é raro encontrar uma criança com déficit motor em consequência da poliomielite. Observei na comunidade a existência de várias crianças com deficiência física em consequência da poliomielite. Ainda não havia o computador. Não havia a inclusão. Aliás, no Laboratório, logo no início, foram atendidas várias crianças prejudicadas quanto ao déficit motor em consequência da poliomielite. Outra coisa importante: não podiam frequentar a escola regular. Estavam destinadas a frequentar a instituição especializada para alunos com déficit intelectual. Não havia uma política de inclusão. Aliás, tudo era muito difícil. No caso das crianças com deficiência física, como consequência da poliomielite que foram atendidas no Laboratório, sempre trabalhamos com os colegas, professores dos cursos da área da saúde, ou melhor, da Fisioterapia e da Terapia Ocupacional. Realizamos vários trabalhos juntos. Inclusive, foi muito importante porque o Laboratório passou a contar com estagiários e bolsistas, alunos do curso da Terapia Ocupacional.

Norma e Luiz Renato: Conforme já citado no início de nossa conversa, em sua caminhada acadêmica, a senhora foi contemplada pela presença de renomados mestres, dentre eles, aquele que, neste ano, o mundo celebra seu centenário de nascimento, nosso ilustre educador Paulo Freire. Seu legado ultrapassa fronteiras da educação, atravessa desafios e remete possibilidades. Ele deixou mais do que ideias e compromisso ético e político, ele transformou pessoas, sobretudo libertando para a vida, para o direito à cidadania. Percebemos que dentre suas lições, Paulo Freire deixou na senhora a inspiração para o desenvolvimento de suas atividades alfabetizadoras, trazendo, assim como ele, uma proposta de alfabetização aqui muito bem apresentada nas ações realizadas pelo Laboratório de Educação Especial e que fez a diferença na vida de muitas crianças, hoje adultos bem-sucedidos. Dentre tantas vidas que transformou, poderia nos relatar algum caso em especial?

MP - Sim. Continuando com o relato das ações, trago como relato o caso de uma criança bastante prejudicada em consequência da poliomielite quanto ao aspecto motor: utilizava as mãos, mas com movimentos bastante reduzidos; não controlava o tronco; e os membros inferiores não possuíam movimentos. Em nosso primeiro encontro, como sempre fiz, a criança sempre tem prioridade, perguntei: Você veio aqui. O que você deseja? Foi uma grande experiência. A resposta foi: Quero aprender a ler e escrever. Opa! O que deveria fazer? Estava diante de um desafio. O apoio da fisioterapia e da terapia ocupacional para o aspecto motor foi fundamental. Foram várias tentativas e, com o auxílio da própria criança, conseguimos a alfabetização, ou seja, ensinar a ler e a escrever. O foco, nessa criança, foi devido ao extremo comprometimento motor. Depois de saber ler, escrever e contar, com a anuência da família, foi realizada a matrícula na escola regular. Foi outro grande obstáculo. Entretanto, quero enfatizar que não foi da escola, mas, sim, de outras variáveis. Mas conseguimos: os colegas professores da fisioterapia e da terapia ocupacional projetaram a cadeira totalmente anatômica e confeccionada pelos profissionais do setor da marcenaria da Universidade. Realmente, quem trabalha com o deficiente físico, tem ciência do que é um aluno que tem problemas quanto à permanência por muito tempo na posição sentada: surgem

Práxis Educativa, Ponta Grossa, v. 16, e2118156, p. 1-10, 2021 Disponível em: < https://www.revistas2.uepg.br/index.php/praxiseducativa> 
os ferimentos por pressão devido à posição continuada por muito tempo - as escaras. Por isso, a cadeira deve ser totalmente anatômica e confortável.

A criança ingressou na escola regular, logo na segunda série, após ser submetida e aprovada a uma avaliação, conforme a legislação, sobre o domínio do conteúdo. Foi tranquila a relação entre escola, criança, professores, colegas, funcionários; enfim, tudo correu muito bem.

Quando surgiu o computador, grande novidade na época, foi possível, junto aos colegas da informática, inserir a população que estava sendo atendida no Laboratório a ter acesso ao computador. Foi quando aquela população de crianças com deficiência física em consequência da poliomielite, agora já adolescente, teve acesso ao computador. O acesso ao computador foi totalmente adaptado. Não havia bancada para encaixar a cadeira de rodas. Os tijolos serviram para o ajuste da altura. A caneta esferográfica devidamente protegida serviu, pressionada na boca pelos dentes, para ter acesso ao teclado. Veja como um movimento pode ser transferido de uma atividade para outra.

O fato interessante foi a tendência para a pintura que a criança já possuía, mas não podia pintar. O mesmo movimento da caneta na boca foi transferido para a ação de pintar. Hoje, a criança já é uma adulta, é uma ótima pintora com a boca e mantém-se graças aos recursos financeiros captados pela organização dos pintores com a boca. Esse relato sobre sua história é contado no livro "Menina de Arte". Lá o leitor poderá entender em quanto tempo a aluna foi alfabetizada. Com ela, utilizei o procedimento de Paulo Freire que havia aprendido no curso realizado no MCP, em 1962/63.

Faço questão, ainda, de relatar sobre a diversidade de problemas das crianças que foram atendidas no Laboratório e que precisavam de um apoio para a aprendizagem. Estavam matriculadas nas escolas e por diversos motivos não podiam frequentá-las com assiduidade: crianças com câncer em tratamento quimioterápico devido à imunidade baixa; crianças com síndrome do X frágil; crianças em terapia hemodialítica; crianças com anemia falciforme; síndrome da criança azul (hoje bem rara); crianças com Transtorno do Espectro Autista (TEA), entre outras. Enfim, um grande número de crianças com síndromes raras que frequentavam o ensino regular e não conseguiam aprender a ler.

Desejo salientar outro grupo de crianças, já com 11 ou 12 anos, que não conseguiam aprender a ler - as afrodescendentes. Foram vários casos semelhantes, porém vou relatar um caso mais recente. Lembro-me de uma menina afrodescendente, já com 12 anos, que não conseguia aprender a ler. Aliás, o problema continua o mesmo, há muito tempo. Agora, com a inclusão, a escola regular não encaminha para a instituição especializada. Devido à discrepância entre idade e ausência na aquisição da leitura, a mãe resolveu procurar o Laboratório. Conforme o resultado da avaliação inicial, ficou evidenciado que a criança não apresentava problema cognitivo. Foi iniciado o atendimento no Laboratório. A criança aprendeu a ler e seguiu sua vida escolar. Após um certo tempo, a mãe retornou ao Laboratório. Eu nem lembrava mais daquela aluna. O retorno ao Laboratório era para me informar que aquela menina que não sabia ler havia entrado na USP/São Paulo. Ela estava ali para me agradecer. Vários são os casos semelhantes.

Pelo que relatei, pode-se constatar que a diversidade do alunado é grande e o professor vai encontrá-la na sua sala de aula. As crianças com cegueira ou com surdez, ou com problema motor são mais visíveis, e os professores ficam mais atentos quanto ao encaminhamento para o apoio especializado. Entretanto, ele deve ficar atento porque há as síndromes raras ou os problemas invisíveis, que a criança necessita de apoio para aprendizagem devido às ausências prolongadas quando necessita frequentar o ambulatório, o hospital, realizar exames de rotina, entre outros.

Práxis Educativa, Ponta Grossa, v. 16, e2118156, p. 1-10, 2021 
Norma e Luiz Renato: Nesse contexto de alfabetização de pessoas com deficiência, a senhora chegou a criar um "método" ou uma "proposta" de atendimento?

MP - Devo, antes de tudo, realizar uma observação. É um “procedimento”. Utilizo o método para a alfabetização já estabelecido com um procedimento específico para o aluno com déficit intelectual. Portanto, o método está estabelecido, mas o procedimento faz a diferença. Sempre me refiro ao termo déficit intelectual porque o termo aplicado anteriormente, deficiência mental, causava uma confusão com a terminologia doença mental. Aliás, a atual, deficiência intelectual, é adequada.

Mas, retorno ao procedimento. Fui buscar nos médicos Itard, Séguin e Montessori, pioneiros nos relatos sobre educação e ensino para alunos com déficit intelectual. Por exemplo, Montessori organizou, construiu, sistematizou e experimentou o seu método com alunos de uma instituição que atendia a crianças com déficit intelectual, as quais apresentaram um excelente desenvolvimento.

Para sistematizar o procedimento que utilizo, tive de partir do conhecimento sobre processo que envolvia a alfabetização; conhecimento sobre a teoria que fundamentava a opção para ensinar a leitura e a escrita, entre outros aspectos importantes, no entorno do aluno, incluindo o social, que contribuíram, de certa forma, para o êxito do procedimento. Tudo isso me levou a uma retrospectiva na minha trajetória como professora. Na década de 1960, a preocupação já era o grande contingente de adultos analfabetos. Havia e até hoje continua havendo a mesma preocupação: o aumento da população de adultos que não sabe ler, pode ser o analfabeto absoluto ou o analfabeto funcional. Observo, atualmente, um grande investimento dos pesquisadores sobre o tema, e os estudos continuam permanentemente sempre acrescentando novos saberes sobre o tema. É uma dinâmica sempre movida pela avidez na direção da erradicação do analfabetismo. E eu tenho acompanhado de perto a angústia das professoras em sala de aula com seus alunos. Praticamente a situação continua preocupante sobre o analfabetismo absoluto ou funcional. Constatei que nossa preocupação é também a preocupação das professoras. Alguma coisa acontece para que os resultados das pesquisas não cheguem até a sala de aula, ou melhor, até os professores.

Atualmente, identifiquei e estou preocupada com outro fato que está acontecendo. Nas pesquisas realizadas sobre o público-alvo da Educação Especial na Educação de Jovens e Adultos (EJA), os achados apontam que um grande número desse alunado é público-alvo da Educação Especial que frequentou o ensino regular desde os 5 anos de idade; e, após os 14 anos, não conseguiu obter o mínimo do conteúdo estudado e, muitas vezes, é analfabeto funcional. Esse público passa para a EJA e continua sem aprender.

Norma e Luiz Renato: Os professores que trabalhavam com alfabetização no ensino regular recebiam algum curso sobre essa temática e que conhecimentos prévios eles demonstravam?

MP - A convite das instituições, ministrei vários cursos sobre a Educação Especial, frequentado por várias professoras do ensino regular. Sempre fiquei curiosa com uma pergunta recorrente realizada pelas professoras logo no início do curso: Qual era a novidade para a alfabetização? $O$ interessante era que essa preocupação não era apenas dos professores da Educação Especial, mas também das professoras do ensino regular.

Durante a ministração dos cursos, em contato direto, observei um fato importante: os professores desconheciam os aspectos fundamentais sobre a alfabetização. É uma das variáveis que deve ser investigada. O desconhecimento impede o entendimento sobre a alfabetização. Durante os cursos que ministrei para a formação continuada dos professores da Educação Especial, sempre evidenciei que o processo é semelhante, mas o procedimento faz a diferença.

Práxis Educativa, Ponta Grossa, v. 16, e2118156, p. 1-10, 2021

Disponível em: <https://www.revistas2.uepg.br/index.php/praxiseducativa> 
Recentemente, tenho visto, pelo YouYube, várias palestras, conferências, debates e cursos sobre alfabetização. Entretanto, parece-me que ainda ocorre uma "desconexão" entre o discurso e a realidade. Ainda não a identifiquei. É prematuro e perigoso partir para o "achismo". Temos de pesquisar para evitar as certezas.

Norma e Luiz Renato: Além da formação continuada de professores, a senhora desenvolveu projetos para os futuros docentes? Os estudantes da Graduação e/ou da Pós-Graduação participavam desse projeto?

MP - Nas décadas de 1980 e 1990, com o investimento dos órgãos governamentais na formação de recursos humanos para a Educação Especial, como já mencionei, ministrei vários cursos, porém todos faziam parte das políticas públicas para a formação de recursos humanos para a Educação Especial. Não era projeto meu, apenas ministrava a disciplina. Pude observar que algumas professoras faziam o curso para obterem promoção funcional. Nem eram da Educação Especial, mas, sim, do ensino regular.

Como fazer um projeto sobre alfabetização para a formação continuada de professores quando a motivação dos participantes é outra: promoção funcional ao final do curso? É a realidade. Isento o professor de qualquer responsabilidade sobre o fato. Ainda há outros motivos. Outro motivo meio confuso que também nunca entendi, seja para os professores da Educação Especial ou para os do ensino regular: a rotatividade. $O$ que isso significa? O professor tem o contrato trabalhista por um ano. Ao final, acaba o contrato e é submetido a novo contrato no próximo ano. Esse fato faz parte do lado dos professores. Para o lado de quem elabora o projeto e tem uma realidade diferente, com estabilidade no vínculo de contrato de trabalho, logicamente acredita que vai dar certo. Mas a angústia de quem vai fazer o curso e não tem estabilidade no con trato de trabalho é muito diferente. O professor que está fazendo o curso, no próximo ano letivo, não sabe onde estará, o que irá fazer. Faz o curso porque vai contabilizar melhor pontuação para obter a classificação ao refazer o contrato trabalhista e continuar a rotatividade. Quem perde com essa incerteza é o professor do ensino regular e o da Educação Especial e, na ponta, o alunado.

Não imagino uma solução para esse fato. É uma situação, um contexto muito diferente da época que as políticas públicas investiam na formação de recursos humanos, no meu caso, para a Educação Especial. Sempre tive uma situação estável no vínculo de trabalho. Pude realizar estudos, atingir metas. Hoje, há muita oscilação quanto ao vínculo empregatício do professor com o trabalho, por conta da rotatividade. Não sei explicar se essa variável tem pequena ou grande influência para a motivação do professor. Se indico os critérios para inclusão dos professores na participação do projeto, fica muito complicado; depende da fonte do recurso financeiro, se público ou particular. É tudo muito complexo. No entanto, como já mencionei anteriormente, a discussão sobre o tema alfabetização e população analfabeta absoluta e/ou funcional continuará por muito tempo. Acredito que terá solução, mas não em curto prazo. São projetos para 20 anos letivos.

Norma e Luiz Renato: E sobre o Grupo de Pesquisa em Educação Especial criado em 1992, um dos primeiros na história da formação dos Grupos de Pesquisa do Conselho Nacional de Desenvolvimento Científico e Tecnológico (CNPq), ele ainda se encontra ativo para a área de Educação Especial? Se sim, pode comentar sobre suas ações e contribuições para o desenvolvimento dessa área, seus objetivos e seus desdobramentos?

MP - Sim. O Grupo de Pesquisa em Educação Especial, juntamente ao Laboratório de Educação Especial, ainda está desenvolvendo pesquisas nas diversas áreas da Educação Especial. Quando denominei tanto o Laboratório como o grupo de pesquisa de "Educação Especial" era para continuar atendendo as atividades do tripé pesquisa, ensino e extensão e, também, atender os

Práxis Educativa, Ponta Grossa, v. 16, e2118156, p. 1-10, 2021 Disponível em: <https://www.revistas2.uepg.br/index.php/praxiseducativa> 
pais, professores - a população que buscava o Laboratório. No caso das altas habilidades/superdotação, por exemplo, não é condição de deficiência, mas estaria na Educação Especial, e o Grupo de Pesquisa Educação Especial desenvolveu pesquisas no Laboratório de Educação Especial sobre altas habilidades/superdotação. Isso porque o Laboratório foi procurado para atender a crianças encaminhadas com suposta nomeação de "superdotação". Anteriormente, no Programa de Pós-Graduação em Educação Especial, não havia pesquisa voltada às altas habilidades/superdotação. Outro exemplo: a surdocegueira. No Brasil, não havia pesquisa sobre surdocegueira. A primeira tese sobre surdocegueira foi desenvolvida pelo Grupo de Pesquisa em Educação Especial, sob a minha orientação. Os desdobramentos existentes são muitos.

Norma e Luiz Renato: Como a professora avalia, de forma geral, toda a contribuição para a área de Educação Especial (seu legado) diante de tantos trabalhos desenvolvidos?

MP - No meu caso, sempre tive um princípio: quando a criança, a família ou a professora buscava o Laboratório para um atendimento, uma orientação, sempre era atendida. O Laboratório sempre foi procurado e sempre atendeu crianças dos vários níveis sociais e com uma diversidade de problemas. Para mim, uma criança sempre é uma criança antes de ser uma "criança com problema" e provável sujeito de pesquisa. Não entendo não atender a criança porque não atende aos critérios de inclusão na pesquisa. Sempre a criança que procura o Laboratório tem atendimento. Em Educação Especial, raramente você encontra uma pesquisa longitudinal. A pesquisa longitudinal é muito complicada para o pesquisador, porque tem de acompanhar os participantes durante muito tempo. Quase inexistente no Mestrado e Doutorado. As exigências para a produção "científica" quase não permitem ao pesquisador realizar uma pesquisa longitudinal.

Norma e Luiz Renato: Por fim e não menos importante, como, atualmente, a professora analisa a Educação Especial no país?

MP - Observo muitos avanços em todos os sentidos na Educação Especial. Entretanto, como pesquisadora e como professora que está em permanente contato com a criança com deficiência e com o professor e que acredita na inclusão, observo que ela não aconteceu. $\mathrm{O}$ que falta para acontecer? O fundamental são os recursos humanos que implica recursos financeiros. Portanto, a inclusão é financeiramente muito onerosa, mas acredito que unindo os esforços a atingiremos.

Norma e Luiz Renato: Professora Piedade, queremos agradecer imensamente por nos ter proporcionado um momento tão especial e esclarecedor! Saiba que assim como há inspiração sua nas ideias do seu ex-professor Paulo Freire, a senhora também nos toca, sua história nos inspira, nos guia, nos transforma! Nossos sinceros agradecimentos!

MP - Agradeço a vocês por esse momento de trocas e à Revista Práxis Educativa pelo interesse e disponibilidade em ouvir minha história de luta na área de Educação Especial. Obrigada. Avante!

Recebido em 10/04/2021

Aceito em 13/06/2021

Publicado online em 17/06/2021

Práxis Educativa, Ponta Grossa, v. 16, e2118156, p. 1-10, 2021

Disponível em: <https://www.revistas2.uepg.br/index.php/praxiseducativa> 